\title{
Monitoring Chemical Reactions with Terahertz Rotational Spectroscopy
}

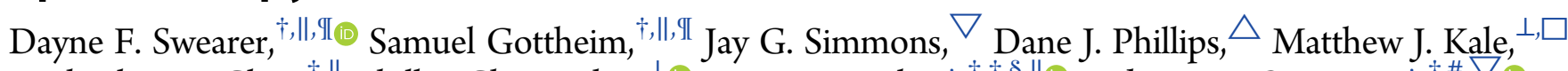
Michael J. McClain, ${ }^{\dagger, \|}$ Phillip Christopher, ${ }^{\perp \odot}$ Naomi J. Halas, ${ }^{*}, \dagger, \downarrow, \S, \| \odot$ and Henry O. Everitt*, ${ }^{*}, \#, \nabla \odot$

${ }^{\dagger}$ Department of Chemistry, ${ }^{\star}$ Department of Electrical and Computer Engineering, ${ }^{\S}$ Department of Physics and Astronomy, and

"Laboratory for Nanophotonics, Rice University, Houston, Texas 77005, United States

${ }^{\perp}$ Department of Chemical Engineering, University of California, Santa Barbara, Santa Barbara, California 93106, United States

\#Department of Physics, Duke University, Durham, North Carolina 27708, United States

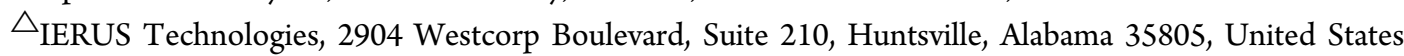

$\nabla_{\text {Army Aviation \& Missile RD\&E Center, Redstone Arsenal, Alabama 35898, United States }}$

\section{Supporting Information}

ABSTRACT: Rotational spectroscopy is introduced as a new in situ method for monitoring gas-phase reactants and products during chemical reactions. Exploiting its unambiguous molecular recognition specificity and extraordinary detection sensitivity, rotational spectroscopy at terahertz frequencies was used to monitor the decomposition of carbonyl sulfide (OCS) over an aluminum nanocrystal (AINC) plasmonic photocatalyst. The intrinsic surface oxide on AlNCs is discovered to have a large number of strongly basic sites that are effective for mediating OCS decomposition. Spectroscopic monitoring revealed two different photothermal decomposition pathways for

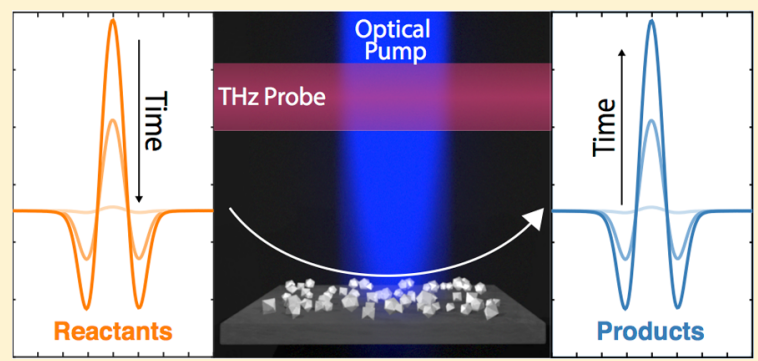
OCS, depending on the absence or presence of $\mathrm{H}_{2} \mathrm{O}$. The strength of rotational spectroscopy is witnessed through its ability to detect and distinguish isotopologues of the same mass from an unlabeled OCS precursor at concentrations of $<1$ nanomolar or partial pressures of $<10 \mu$ Torr. These attributes recommend rotational spectroscopy as a compelling alternative for monitoring gas-phase chemical reactants and products in real time.

KEYWORDS: plasmonics, photocatalysis, rotational spectroscopy, carbonyl sulfide, aluminum nanocrystals

hromatography and mass spectrometry are universally established as the gold standards for analyzing the products of chemical reactions in the laboratory. While both chromatography and mass spectrometry have proven invaluable over the past several decades, there are limitations to each technique. In chromatography, molecular species are separated and analyzed based on elution dynamics on a chromatography column; however, it can be difficult to discriminate between enantiomers, particularly among isotopically labeled products, without highly specialized equipment. Mass spectrometry can easily distinguish between many isotopically labeled species, but small molecules can frequently have overlapping mass fragments (i.e., $\mathrm{H}_{2} \mathrm{O}$ and $\mathrm{NH}_{3}$ or $\mathrm{CO}$ and $\mathrm{N}_{2}$ ) that complicate interpretation. Chromatography can be coupled with mass spectrometry to separate and identify reactants and products, but such measurements must be performed ex situ, excluding the possibility of real-time monitoring of reaction processes.

Here we introduce terahertz $(\mathrm{THz})$ rotational spectroscopy as a new tool for monitoring gas-phase reactants and products of chemical reactions in situ. Rotational spectroscopy has several distinct advantages not achievable with existing techniques. It has the ability to distinguish molecules with absolute recognition sensitivity, including the facile discrim- ination of isotopologues. ${ }^{1,2}$ This is particularly important in the study of molecular decomposition reactions, including the mediation of toxic or environmentally hazardous chemicals, for which multiple small-molecule reaction products may be formed. ${ }^{3}$ Rotational transitions and their associated line strengths are very well known, allowing for highly sensitive, calibrated, quantitative measurements to be performed for concentrations $<1$ nanomolar or partial pressures of $<10$ $\mu$ Torr. ${ }^{4,5}$ This extraordinary sensitivity makes it possible to detect low concentrations of desired or even harmful byproducts in chemical processes. Rotational spectroscopy can be integrated within a gas-phase reaction chamber to monitor the evolution of multiple reactants and products as a function of time. Although detection is limited to gas-phase molecules with permanent dipole moments, this combination of unambiguous recognition specificity and sensitive detection makes rotational spectroscopy an extremely powerful tool for deducing chemical reaction pathways and quantitatively measuring reaction outcomes.

Received: March 16, 2018

Published: May 18, 2018 
To illustrate these advantages, we explored photocatalytic molecular decomposition by laser-illuminated metal nanoparticles. The exploitation of collective oscillations in freeelectron density within metallic nanostructures, also known as localized surface plasmons resonances (LSPRs), has become a major topic in nanoscience over the last two decades. ${ }^{6-9}$ The recent introduction of plasmonic nanomaterials as heterogeneous photocatalysts in chemistry has initiated a new and potentially transformative field of study, where plasmonic nanomaterials may greatly reduce the energy requirements of chemical reactions and control product specificities. ${ }^{10}$ Plasmonic photocatalysts can drive chemical reactions on their surfaces in at least two ways: by the generation of hot carriers that induce bond dissociation following transfer to an unoccupied molecular orbital of an adsorbate or by localized photothermal excitation of adsorbate molecules. Numerous plasmon-mediated chemical reactions have been demonstrated, including water splitting, ${ }^{11}$ hydrogen generation, ${ }^{12}$ ethylene epoxidation, ${ }^{13}$ CO oxidation, ${ }^{14}$ selective hydrogenation, ${ }^{15}$ reverse water-gas shift, ${ }^{16}$ and the Sabatier reaction. ${ }^{17}$ It was recently shown that plasmonic nanomaterials can even be combined with conventional catalytic nanoislands or surface epilayers to form "antenna-reactor" complexes to expand the scope of this approach further. ${ }^{15}$

In this report, aluminum nanocrystals (AlNCs) ${ }^{18}$ were used as an earth-abundant plasmonic photocatalyst to decompose carbonyl sulfide (OCS). OCS was selected as a model compound to demonstrate the applicability of rotational spectroscopy to monitor plasmon-mediated decomposition in situ. Infrared spectroscopy and temperature-programmed desorption studies indicate heightened catalytic activity of the amorphous AlNC oxide coating, while rotational spectrometry data show how the presence or absence of adsorbed water determines the decomposition pathways of OCS. OCS is classified as a toxic industrial compound (TIC): a material that exhibits chemical hazards (carcinogen, corrosive, etc.) or physical hazards (explosive, flammable, etc.). The detection and remediation of TICs is critically important for mitigating workplace hazards and preventing catastrophic environmental events.

\section{RESULTS AND DISCUSSION}

Photocatalytic Reaction Chamber. A photocatalytic reaction chamber was constructed to enable in situ monitoring of gas-phase plasmon-mediated reactions by $\mathrm{THz}$ rotational spectroscopy. Rotational absorption spectroscopy offers absolute recognition specificity and quantitative concentration measurements from known transition frequencies and absorption coefficients, respectively. The recognition specificity derives from the fact that the quantized energy levels for rotational motion depend sensitively on the molecule's moments of inertia. ${ }^{1,2}$ Because the spacing between those energy levels are small compared to $k T$, dozens of levels are thermally populated at room temperature, allowing a comparable number of rotational transitions to be measured. Since these rotational lines are narrow $(\sim 1 \mathrm{MHz})$ at low pressures $(<0.1$ Torr $)$, absorption line frequencies are routinely measured in the $\mathrm{THz}$ spectral region with at least seven digits of accuracy ( $<10 \mathrm{kHz}$ precision). This allows for a plethora of lines to be measured and the molecule to be unambiguously identified. Concentration measurements are made possible by tables of calculated transition line strengths available for most molecules of interest. ${ }^{19,20}$ Experimentally calibrated measure- ments of these line strengths provide the means to ascertain molecular concentrations quantitatively. Moreover, Schottky diode detectors coupled with standard phase-sensitive source frequency modulation techniques permit sensitive detection of analytes to very low concentrations.

A generalized schematic of the reaction chamber is shown in Figure 1a. The experimental apparatus consists of six major components: (i) THz source, (ii) UV/visible light source, (iii) ultra-high vacuum (UHV) reaction chamber, (iv) sample stage for the catalyst, (v) THz detector, (vi) gas delivery and vacuum manifold system. The reaction chamber consists of a five-way cross-shaped tubing that houses the plasmonic photocatalyst

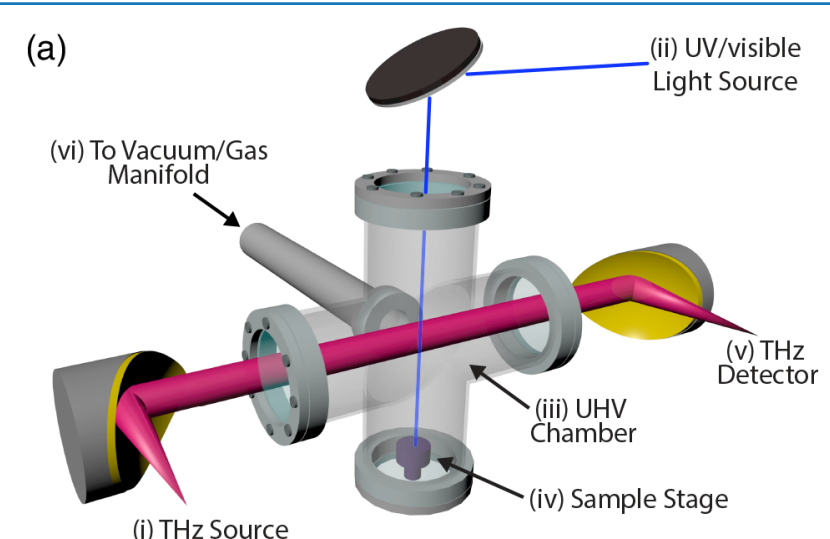

(b)

(c)
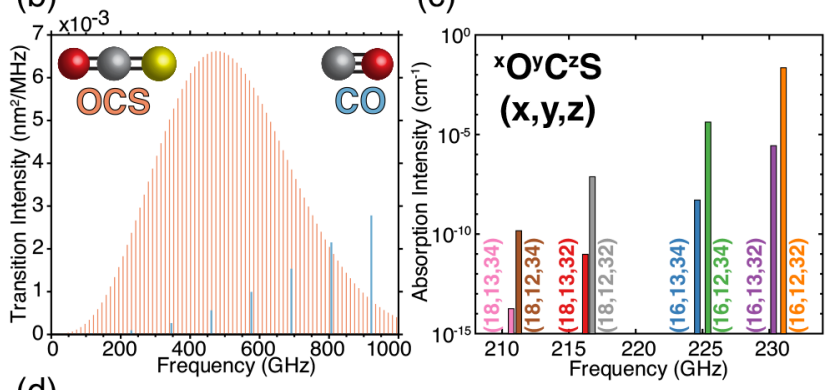

(d)

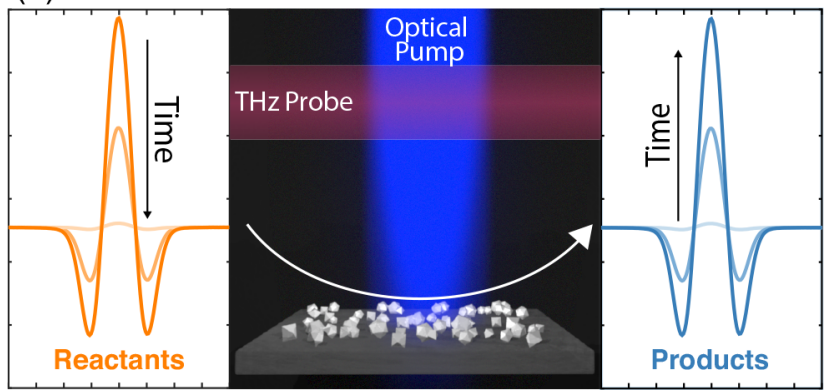

Figure 1. Rotational spectrometer for plasmonic photocatalysis. (a) Illustration of the reaction chamber used in this study. (b) An example histogram of integrated absorption intensity for carbonyl sulfide (orange) and carbon monoxide (blue) at $0-1000 \mathrm{GHz}$. (c) Example of a single rotational transition $(J=18 \rightarrow 19)$ for eight isotopologues of carbonyl sulfide. Integrated line strengths plotted as a histogram in (b) and (c) were acquired from refs 4 and 19, respectively. (d) A tunable, frequency-doubled Ti:sapphire laser is used as an optical pump to excite the localized surface plasmon resonance of the chosen catalyst. A $\mathrm{THz}$ probe simultaneously monitors the composition of gas in the UHV reaction chamber. The modulated absorption signal from reactants (shown left; orange) decreases as a function of time, while the modulated absorption signal from any products (shown right; blue) increases as a function of time. 
and allows the introduction and removal of gases. The four inplane arms have optical ports that permit the transmission of the optical pump (vertical) and $\mathrm{THz}$ probe (horizontal) beams. The catalyst is positioned above the bottom viewport and attached on a custom feedthrough consisting of a heating stage and a type- $K$ thermocouple. The fifth arm of the reaction chamber is connected to an additional assembly to allow for the introduction $\left(<10^{-2}\right.$ Torr) or evacuation (base pressure $<10^{-5}$ Torr) of gases through a vacuum manifold. While low operating pressures allow for absolute molecular recognition of narrow, well-characterized rotational transitions, reaction rates are constrained by gas diffusion and surface migration to active sites on the illuminated catalyst. A full schematic of the reaction chamber is shown in Figure S2 as well as an electronics diagram for the experimental apparatus in Figure S3.

To demonstrate the recognition specificity of this technique, a histogram of integrated intensities for OCS and CO rotational transitions as a function of frequency between 0 and $1 \mathrm{THz}$ is shown in Figure $1 \mathrm{~b}$ as orange and blue bars, respectively. The different moments of inertia of these two linear molecules produce drastically different rotational spectra, shown by the 81 transitions of OCS and eight transitions of $\mathrm{CO}$ in the same frequency range. Even the small moment of inertia differences in isotopic variants of the same molecule produce large, easily distinguishable frequency shifts for a given rotational transition. For example, the $J=18 \rightarrow 19$ transition for eight isotopologues of OCS have been plotted, showing the integrated transition intensity as a function of frequency (Figure 1c). ${ }^{20}$ Since the low-pressure line widths of these eight transitions are $<1 \mathrm{MHz}$, yet the rotational transition frequencies for each isotopologue are distributed across $20 \mathrm{GHz}$, their distinct spectral fingerprints are easily resolved.

The strength of rotational transitions, which depend on the moments of inertia and centrifugal distortions of the molecule, its dipole moment and transition matrix elements, state degeneracies, and Boltzmann population distributions, may be calculated precisely using quantum mechanical models. ${ }^{1,2,19,20}$ For example, the transition frequencies and strengths for hundreds of molecules are available from the Jet Propulsion Laboratory (JPL) molecular spectroscopy database. ${ }^{4}$ In Figure $1 b, c$, we are only plotting integrated line strength intensities as a function of frequency because the actual line shape is unresolvable for the scale of these plots. Experimentally, we measure the line strength of known rotational transitions by sweeping a frequency-tunable terahertz source across their Doppler- or pressure-broadened absorption line shapes and measure the fractional absorption of the probe beam as it is transmitted through the $10 \mathrm{~cm}$ long absorption chamber and detected with a Schottky diode detector.

To detect weak spectral lines above a background of strong, broad standing-wave power variations in the spectrometer, we adopted the well-known spectroscopic techniques of source frequency modulation and phase-sensitive detection. ${ }^{21}$ By selecting a modulation depth comparable to the line width of the rotational transition and using a lock-in amplifier to measure the strength of the modulated signal at twice the modulation frequency, we record a line shape that approximates the second derivative of the actual line shape while flattening the baseline. This method allows differential amplification and filtering of the line itself, which is then fit with a matched Voigt profile to recover the unmodulated line shape from which the integrated line strength may be measured. ${ }^{22}$ To convert these line strengths into absolute partial pressures of the associated gases in the chamber, an initial calibration of the spectrometer is performed in which a gas of known pressure is introduced into the chamber and its measured integrated line strength is compared with that of the JPL database. From this comparison, molecule- and spectrometer-dependent conversion factors are obtained that are then applied to each measured molecular gas of interest. In this manner, our experimental apparatus can monitor photocatalytic chemical transformations in situ while using the $\mathrm{THz}$ probe to monitor the decrease of reactants and increase of products simultaneously (Figure 1d). On the left and right of Figure 1d we show a generalized spectral line shape that is obtained using frequency-modulated rotational spectroscopy. Further discussion regarding the specific parameters affecting frequency-modulated rotational spectroscopy and how this technique obtains quantitative molecular concentrations over many orders of magnitude is included in the Supporting Information and will be detailed extensively in an upcoming publication.

A critical aspect of this experimental technique is the ability to use any molecular reference to calibrate for all detectable molecular species. Calibration, which correlates measured line strengths to known chamber pressures for a well-known molecular species, is necessary to quantify the concentration of all reactants, gas-phase intermediates, and products, especially for species where independent calibration is difficult (e.g., $\mathrm{H}_{2} \mathrm{O}$ ). To demonstrate this, a calibration curve that relates measured OCS line strengths to measured OCS pressure predicted $\mathrm{CO}$ concentrations from subsequently measured line strengths to within $\sim 10 \%$, as confirmed with a separate $\mathrm{CO}$ calibration curve. This accuracy was achieved by simply adjusting for the ratio of the calculated line strengths in the JPL molecular spectroscopy database and for the ratio of the detected power in an empty chamber at the associated OCS and $\mathrm{CO}$ transition frequencies. ${ }^{4}$ By this internal calibration procedure the measured line strength for any molecule measures its concentration. The small $\sim 10 \%$ disagreement, caused by small power variations and modulation imperfections in the spectrometer during an experiment, was smaller than the day-to-day drift in this early prototype, so a common calibration curve was used in the measurements reported here (see Figure S1) to illustrate the concept at the cost of concentration uncertainties no larger than $\pm 20 \%$.

Plasmon-Mediated Decomposition of Carbonyl Sulfide. OCS was chosen as a model compound due to the strong rotational transition strengths of OCS and its possible decomposition products (i.e., $\mathrm{CO}$ and/or $\mathrm{H}_{2} \mathrm{~S}$ ). The chemistry of OCS has been well explored, ${ }^{23,24}$ and several methods for its mitigation have been reported, such as hydrogenation, ${ }^{25}$ hydrolysis, ${ }^{26}$ photolysis, $^{27}$ and oxidation. ${ }^{28,29}$ Of these, hydrolysis is generally recognized as the most promising due to its high conversion efficiencies and mild reaction conditions. ${ }^{30}$ The preferred catalysts for OCS hydrolysis are metal oxides, particularly aluminum oxide, although titanium and magnesium oxides are used today in certain industrial processes. $^{23}$

Previous studies on OCS decomposition over aluminum oxide powders have revealed that the active sites are basic ${ }^{31}$ and that the rate of OCS decomposition is related to the basicity of those active sites. ${ }^{32}$ Therefore, the likelihood that the intrinsic 2-4 nm thick aluminum oxide surface layers of AlNCs also have basic sites makes them strong candidates for OCS decomposition. In addition to their surface chemistry, AlNCs 
represent an earth-abundant alternative to $\mathrm{Au}$ and $\mathrm{Ag}$ for plasmon-mediated catalysis.

The AlNCs used in this study were synthesized using a previously described protocol. ${ }^{18}$ A transmission electron micrograph shows the general morphology of the $\sim 70 \mathrm{~nm}$ diameter AlNCs used in this experiment (Figure 2a), and
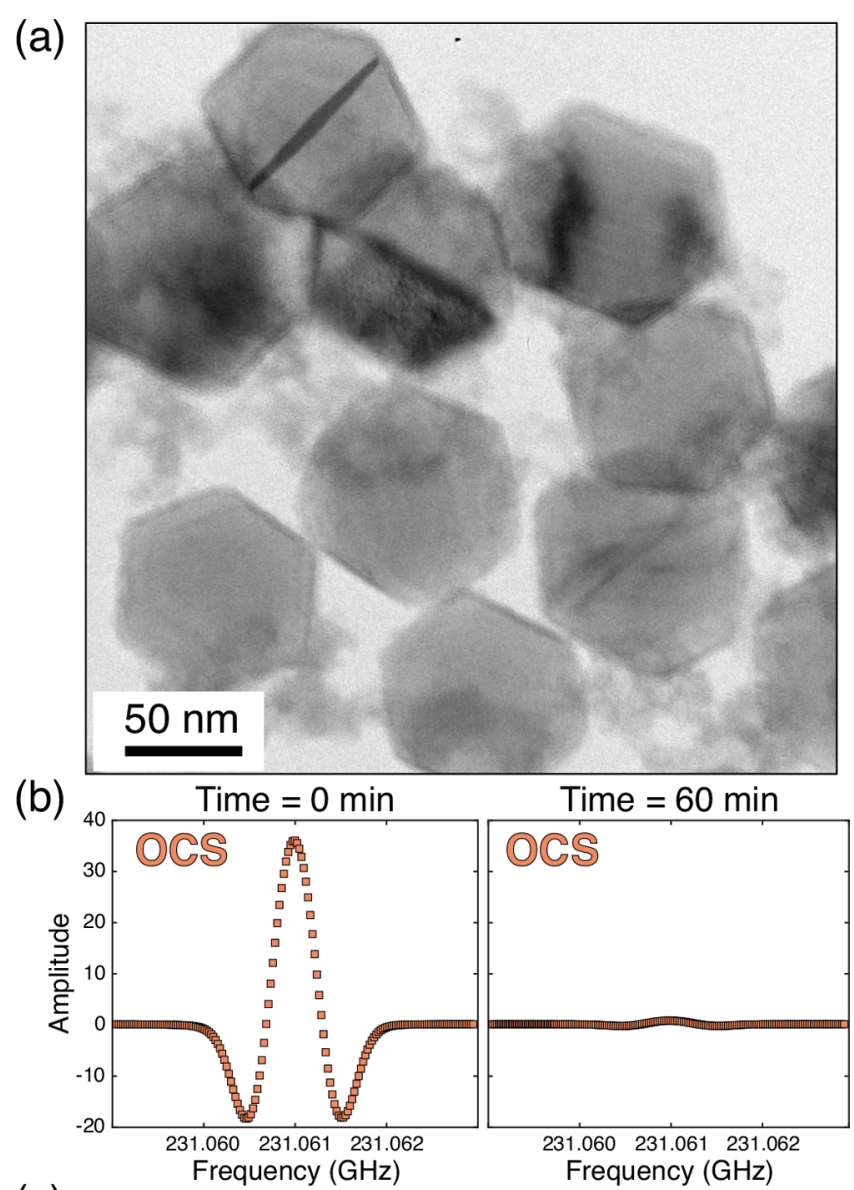

(c)

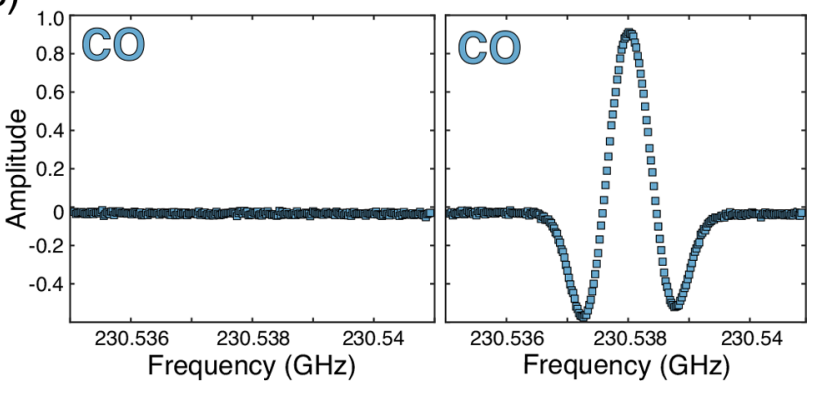

Figure 2. Plasmonic decomposition of carbonyl sulfide. (a) Transmission electron micrograph of $\sim 70 \mathrm{~nm}$ diameter aluminum nanocrystals used as the catalyst in this study. (b) Amplitude of the OCS $J=18 \rightarrow 19$ transition at $231.061 \mathrm{GHz}$ before (left) and after 60 min of illumination (right). (c) Amplitude of the CO $J=1 \rightarrow 2$ transition at $230.538 \mathrm{GHz}$ before (left) and after $60 \mathrm{~min}$ of illumination (right).

AlNCs of this diameter possess a plasmon resonance at $\lambda=400$ $\mathrm{nm}$ (Figure S4). During the reaction, the AlNCs were supported at $10 \mathrm{wt} \%$ loading on acid-washed and calcined $\mathrm{SiO}_{2}$ with a particle size distribution between 0.5 and $10 \mu \mathrm{m}$ and $80 \%$ between 1 and $5 \mu \mathrm{m} .{ }^{33}$ OCS decomposition takes place on the native oxide surface of the AlNCs. In this sense, the AlNCs are behaving as "antenna-reactor" nanocomplexes ${ }^{15}$ where the plasmon resonance of the $\mathrm{Al}$ core is enhancing catalytic activity on the intrinsic surface oxide. After OCS adsorption to the oxide surface, it has been proposed in the well-studied hydrolysis mechanism that a surface hydrogen thiocarbonate (HTC) species is formed. ${ }^{28,31,34}$ However, after HTC formation, the mechanistic pathway can diverge based on water content in the reaction system. ${ }^{25}$ These two pathways have been referred to as the (1) "CO reaction" and (2) the " $\mathrm{CO}_{2}$ reaction". 35

$$
\begin{aligned}
& \mathrm{OCS} \rightarrow \mathrm{CO}+\mathrm{S}^{*} \\
& \mathrm{OCS}+\mathrm{H}_{2} \mathrm{O} \rightarrow \mathrm{CO}_{2}+\mathrm{H}_{2} \mathrm{~S}
\end{aligned}
$$

To demonstrate the CO reaction (1), the catalyst was loaded into the reaction chamber, and the vacuum system and catalyst stage were held at $\sim 300{ }^{\circ} \mathrm{C}$ for $24 \mathrm{~h}$ to desorb $\mathrm{H}_{2} \mathrm{O}$ and other possible molecular contaminants from their surfaces. After allowing the experimental apparatus to return to room temperature, a nominal pressure of 30.7 mTorr OCS was introduced into the reaction chamber. While sequentially measuring selected rotational transitions of OCS, CO, $\mathrm{H}_{2} \mathrm{O}$, and $\mathrm{H}_{2} \mathrm{~S}$ approximately once per minute in the $210-360 \mathrm{GHz}$ region spanned by the spectrometer, a pulsed laser with an average power density of $\sim 5 \mathrm{~W} / \mathrm{cm}^{2}$ and a wavelength of 404 $\mathrm{nm}$ was scanned over the catalyst surface to excite the LSPR of the AlNCs. The pressure in the chamber, which can vary from experiment to experiment, was measured by a capacitance manometer capable of pressure measurements between 0 and 100 mTorr.

At the beginning of the experiment, only OCS is detectable (Figure 2b,c left), with $\mathrm{CO}$ excluded to its detection threshold of $22 \mu$ Torr, or $1.2 \mathrm{pmol} / \mathrm{cm}^{3}$ (1.2 nanomolar) given our chamber volume of $1.8 \mathrm{~L}$. Over the course of a reaction, only OCS and CO spectra were observed, and the line strength of OCS diminishes while CO increases and becomes the dominant species in the chamber (Figure 2b,c right). By referencing the integrated Voigt profiles obtained from measured OCS and CO spectra during the decomposition reaction to the calibration curves measured from pure OCS and $\mathrm{CO}$ (Figure S1), respectively, the experimental pressures throughout the reaction could be calculated (Figure 3a). Prior to laser illumination, adsorption onto the catalyst reduced the OCS pressure. As the laser scanned over the catalyst surface, photothermal decomposition of OCS increased the partial pressure of $\mathrm{CO}$ to $24.2 \mathrm{mT}$ orr after $2 \mathrm{~h}$, while the initial OCS partial pressure, measured using the integrated Voigt profile to be $37.1 \mathrm{mTorr}$, fell to $5.1 \mathrm{mTorr}$, confirming the causal relationship between the observed OCS decomposition and $\mathrm{CO}$ evolution. Neither $\mathrm{H}_{2} \mathrm{O}$ nor $\mathrm{H}_{2} \mathrm{~S}$ was observed; their line strengths and associated concentrations stayed below their respective detection limits of 1.06 and $0.45 \mathrm{pmol} / \mathrm{cm}^{3}$ or 19.8 and $8.3 \mu$ Torr, respectively. Importantly, the detection threshold is molecule-dependent and influenced by several parameters, including the strength of the molecule's dipole moment, temperature, the fraction of molecules in the lower state, the power of the source, the noise in the detector/ amplifier system, the modulation depth, the time constant of the lock-in amplifier, and the integration time of the acquisition system (see Supporting Information for specific details).

When the catalyst is not pretreated at high temperatures and partial pressures of $\mathrm{H}_{2} \mathrm{O}$ are above the detection threshold of $\sim 1 \mathrm{pmol} / \mathrm{cm}^{2}$, the "CO reaction" is suppressed in favor of the 


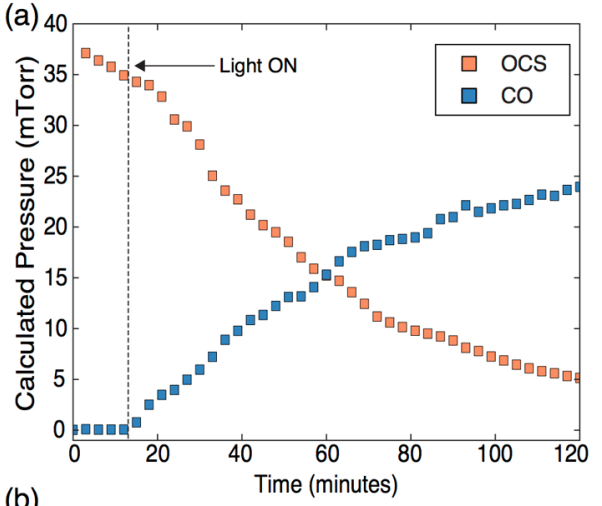

(b)

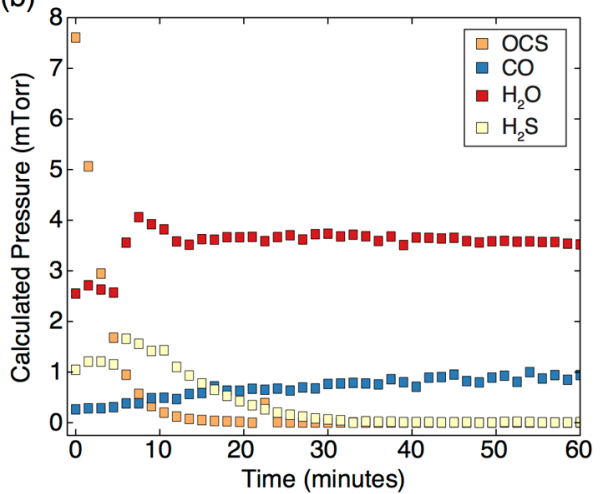

Figure 3. Temporal decomposition of carbonyl sulfide. (a) Decomposition and evolution of OCS and CO after pretreating the catalyst and chamber to remove excess $\mathrm{H}_{2} \mathrm{O}$. Laser illumination of the catalyst began $\sim 10 \mathrm{~min}$ after introducing OCS into the chamber. (b) Under constant laser illumination, OCS decomposition in the presence of $\mathrm{H}_{2} \mathrm{O}$ shows appreciable yields of $\mathrm{H}_{2} \mathrm{~S}$ while minimizing yields of $\mathrm{CO}$. OCS and $\mathrm{CO}$ pressures were obtained using their measured line strengths and respective calibration curves. $\mathrm{H}_{2} \mathrm{O}$ and $\mathrm{H}_{2} \mathrm{~S}$ pressures were obtained using their measured line strengths and the internal calibration method referenced to the OCS calibration curve (Figure S1).

" $\mathrm{CO}_{2}$ reaction" (Figure $3 \mathrm{~b}$ ). In the well-studied hydrolysis mechanism, $\mathrm{H}_{2} \mathrm{O}$ plays the crucial role of protonating the HTC species, producing $\mathrm{H}_{2} \mathrm{~S}$ and $\mathrm{CO}_{2}$ as the sole gaseous byproducts. In our experiments, when the photocatalyst is not heated under vacuum and $\mathrm{H}_{2} \mathrm{O}$ remains a prominent species after the introduction of OCS, we observe reactivity consistent with a hydrolysis mechanism. During the experiment, a nominal pressure of $8.6 \mathrm{mT}$ Torr of OCS was introduced to the reaction chamber, as measured by the capacitance manometer, but Figure $3 \mathrm{~b}$ indicates the maximum pressure calculated by the integrated Voigt fit method was only 7.6 mTorr. A constant pressure of $\sim 3.5$ mTorr $\mathrm{H}_{2} \mathrm{O}$ was measured throughout the experiment, suggesting an equilibrium was established and that the reaction chamber contained appreciable $\mathrm{H}_{2} \mathrm{O}$ on the catalyst surface and chamber walls. The production of $\mathrm{CO}$ is greatly suppressed over the course of 60 min, and detection of a maximum partial pressure of $\sim 1.7$ mTorr $\mathrm{H}_{2} \mathrm{~S}$ is observed. The signal from $\mathrm{H}_{2} \mathrm{~S}$ dissipates over the course of the reaction due to strong adsorption on the catalyst and chamber walls (Figure S5). After $60 \mathrm{~min}$ the only molecular signature remaining was $\mathrm{H}_{2} \mathrm{O}$. In this case, $\mathrm{H}_{2} \mathrm{O}$ promotes OCS hydrolysis on the AlNC surface, producing $\mathrm{CO}_{2}$ and $\mathrm{H}_{2} \mathrm{~S}$, of which only the latter could be detected using rotational spectroscopy. The $\mathrm{H}_{2} \mathrm{~S}$ yield was not observed to be stoichiometric because of strong adsorption to the catalyst and chamber surfaces while being produced. The remaining partial pressure measured by the capacitance manometer in the reaction chamber is most likely $\mathrm{CO}_{2}$, but its presence could not be verified explicitly using rotational spectroscopy. The effect of $\mathrm{H}_{2} \mathrm{O}$ in OCS decomposition is 3-fold. First, $\mathrm{H}_{2} \mathrm{O}$ acts as a competitive adsorbate with OCS, poisoning basic sites. ${ }^{36}$ Second, $\mathrm{H}_{2} \mathrm{O}$ promotes $\mathrm{CO}_{2}$ production through the traditional hydrolysis mechanism, consuming OCS in the process. ${ }^{31}$ Third, any formation of $\mathrm{CO}$ in the presence of $\mathrm{H}_{2} \mathrm{O}$ may undergo the reverse water gas shift reaction $\left(\mathrm{CO}+\mathrm{H}_{2} \mathrm{O} \Leftrightarrow \mathrm{CO}_{2}+\mathrm{H}_{2}\right)$, producing $\mathrm{H}_{2}$ and $\mathrm{CO}_{2}$, ${ }^{25}$ neither of which can be measured directly in our system due to their lack of a permanent dipole. Under these conditions, the reaction reaches a steady state after $\sim 30$ min, most likely after proceeding through rapid OCS hydrolysis and subsequently reaching equilibrium of the watergas shift reaction.

Aluminum Nanocrystal Surface Chemistry. When the AlNC catalyst was pretreated at $300{ }^{\circ} \mathrm{C}$, driving off adsorbed $\mathrm{H}_{2} \mathrm{O}$ and activating strong basic sites on its surface oxide in the process, $\mathrm{CO}$ was the sole gaseous byproduct detected by the rotational spectrometer (Figure 3a). Reports of high-temperature OCS decomposition have shown that the "CO reaction" is not only possible, it is kinetically preferred to the " $\mathrm{CO}_{2}$ reaction". ${ }^{35,37}$ We hypothesize that a thiocarbonate surface intermediate is created by the interaction of OCS with the basic oxide on the AlNCs, and photothermal heating subsequently forms and desorbs CO. High laser power density illumination of plasmonic AlNCs under UHV likely induces high surface temperatures, promoting a photothermal pathway. Sulfur is known to be left behind on the surface as sulfites $\left(\mathrm{SO}_{3}{ }^{-}\right)$and sulfates $\left(\mathrm{SO}_{4}{ }^{2-}\right)$, leading to catalyst deactivation by the creation of Brønsted acid sites at the expense of the active basic sites. ${ }^{38}$ Deactivation of the AlNC catalyst over time and the inability of simple heating to regenerate the original activity have been observed, supporting this high-temperature decomposition pathway. Additionally, no sulfur-containing species (i.e., $\mathrm{H}_{2} \mathrm{~S}$ ) are observed as gas-phase products when high-temperature pretreatment sufficiently removes $\mathrm{H}_{2} \mathrm{O}$ from the reaction chamber. X-ray photoelectron spectroscopy was attempted in order to probe the catalyst surface after OCS decomposition to check for sulfur, but since the concentration of reactants is on the order of $50 \mathrm{mmol}$ of sulfur per gram of catalyst, and distributed throughout the entire volume, any newly formed surface species would be beyond the detection limit of surfacesensitive techniques.

Since the active sites for OCS decomposition on metal oxides are basic in nature, typically monodentate surface hydroxyls, ${ }^{31}$ the observed high activity of OCS decomposition on AlNCs suggests a high abundance of strongly basic sites. To understand these active sites on the AlNC plasmonic photocatalyst, the quantity and constitution of acidic and basic sites were probed using a combination of probe-molecule temperature-programmed desorption (TPD) and infrared (IR) spectroscopy experiments. Identical measurements were conducted on commercial $\gamma-\mathrm{Al}_{2} \mathrm{O}_{3}$ powders to compare with the amorphous oxide surrounding the AlNC photocatalyst.

To quantify the number of basic sites, AlNCs and commercial $\gamma-\mathrm{Al}_{2} \mathrm{O}_{3}$ were pretreated at different temperatures between 300 and $500{ }^{\circ} \mathrm{C}$ in $\mathrm{He}$ and then were cooled to $30{ }^{\circ} \mathrm{C}$ under a continuous flow of $\mathrm{He}$ (to degas the sample). Pulsed $\mathrm{CO}_{2}$ chemisorption was then performed until saturation, followed by a $\mathrm{CO}_{2}$ TPD measurement. $\mathrm{CO}_{2}$ chemisorption experiments, normalized to surface area, revealed that AlNCs 
(a)

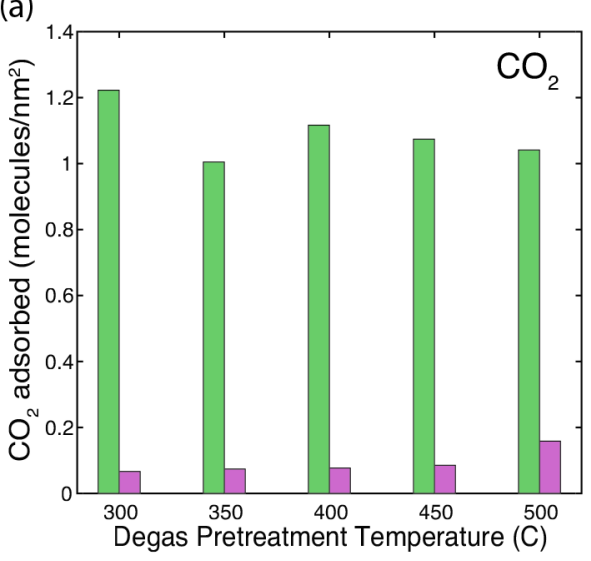

(b)

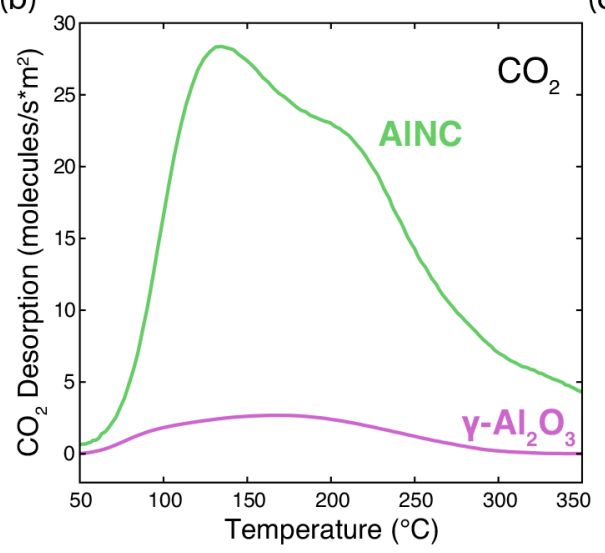

(c)

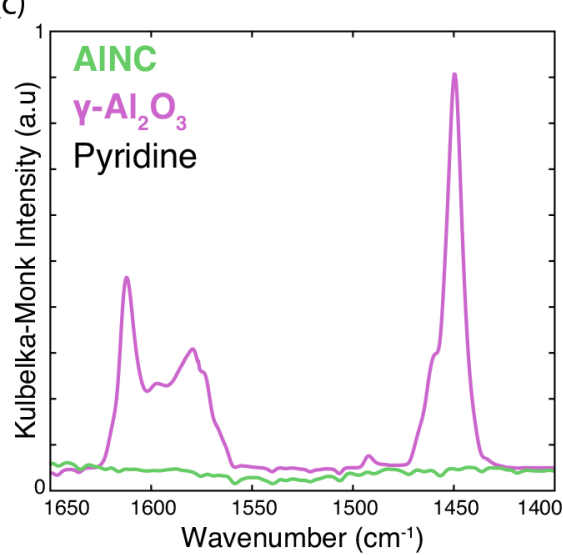

(d)

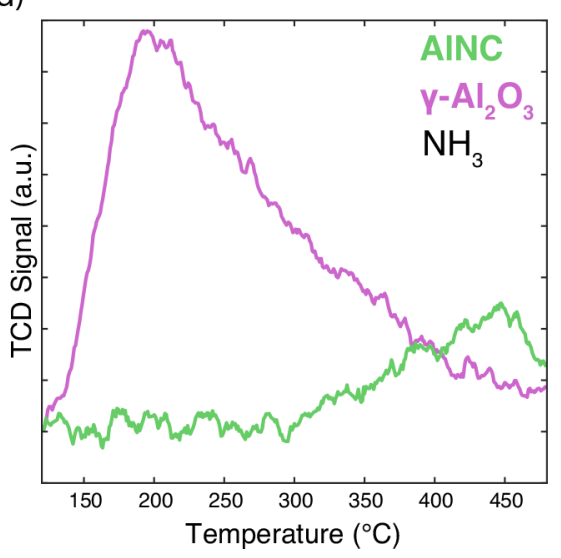

(e)

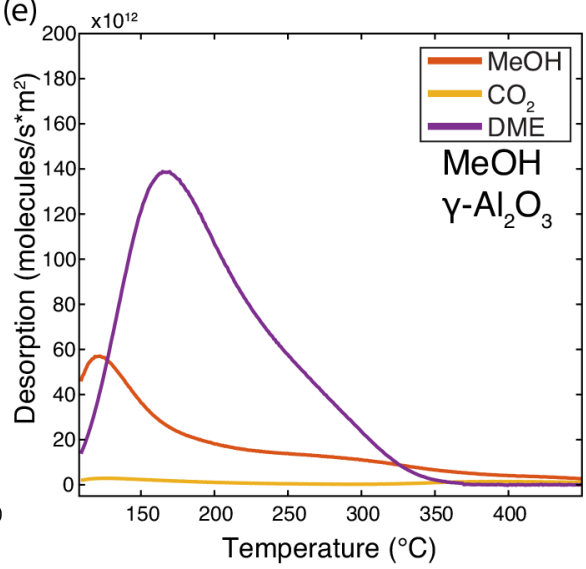

(f)

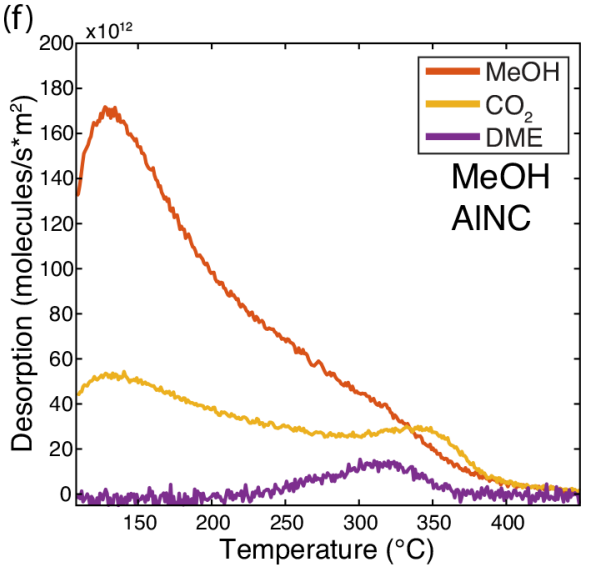

Figure 4. Surface chemistry of aluminum nanocrystals. (a) $\mathrm{CO}_{2}$ pulsed chemisorption at different pretreatment temperatures of AlNCs (green) and $\gamma$ - $\mathrm{Al}_{2} \mathrm{O}_{3}$ (purple) to measure the number of basic sites on the oxide surface. (b) Representative temperature-programmed desorption of $\mathrm{CO}_{2}$ from AlNCs (green) and $\gamma-\mathrm{Al}_{2} \mathrm{O}_{3}$ (purple) pretreated at $300{ }^{\circ} \mathrm{C}$ under $50 \mathrm{sccm}$ He flow while ramping to $350{ }^{\circ} \mathrm{C}$ at a rate of $60{ }^{\circ} \mathrm{C} / \mathrm{min}$. (c) Pyridine adsorption infrared spectroscopy showing chemisorbed pyridine on acidic sites on AlNCs (green) and $\gamma-\mathrm{Al}_{2} \mathrm{O}_{3}$ (purple). (d) $\mathrm{NH}_{3}$ temperatureprogrammed adsorption showing acidic site reactivity on AlNCs (green) and $\gamma-\mathrm{Al}_{2} \mathrm{O}_{3}$ (purple). (e) Methanol temperature-programmed desorption on $\gamma-\mathrm{Al}_{2} \mathrm{O}_{3}\left(300{ }^{\circ} \mathrm{C}\right.$ pretreatment) showing primarily dimethyl ether (DME) desorption, confirming mostly acidic surface sites. (f) Methanol temperature-programmed desorption on AlNCs $\left(30{ }^{\circ} \mathrm{C}\right.$ pretreatment) showing selectivity for $\mathrm{CO}_{2}$ formation, suggesting mostly basic sites on the amorphous oxide surface.

(green) have about $10 \times$ more basic sites than commercial $\gamma$ $\mathrm{Al}_{2} \mathrm{O}_{3}$ (purple) under similar pretreatment conditions (Figure 4a). $\mathrm{CO}_{2}$ TPD of AlNCs and $\gamma-\mathrm{Al}_{2} \mathrm{O}_{3}$ pretreated at $300{ }^{\circ} \mathrm{C}$ reveals strikingly different behavior in the strength of active site basicity (Figure 4b). Desorption of $\mathrm{CO}_{2}$ from $\gamma-\mathrm{Al}_{2} \mathrm{O}_{3}$ showed a broad maximum at $\sim 150{ }^{\circ} \mathrm{C}$. However, $\mathrm{CO}_{2}$ desorption from AlNCs showed two distinct desorption peaks: a maximum at $\sim 130{ }^{\circ} \mathrm{C}$ and a shoulder occurring at $\sim 200{ }^{\circ} \mathrm{C}$. AlNCs and commercial $\gamma-\mathrm{Al}_{2} \mathrm{O}_{3}$ pretreated at $500{ }^{\circ} \mathrm{C}$ show a similar trend to the $300{ }^{\circ} \mathrm{C}$ case, although the higher temperature shoulder present for AlNCs has shifted to a maximum at $\sim 330{ }^{\circ} \mathrm{C}$ (Figure S6). Together, $\mathrm{CO}_{2}$ chemisorption and $\mathrm{CO}_{2}$ TPD measurements reveal three compelling attributes of AlNC catalysts: their oxides have an order of magnitude more basic sites than commercial $\gamma-\mathrm{Al}_{2} \mathrm{O}_{3}$ of equivalent surface area, some of their basic sites are much stronger, and their strength can be tuned as a function of pretreatment temperature.

To probe the acidic sites on AlNCs and commercial $\gamma-\mathrm{Al}_{2} \mathrm{O}_{3}$, a combination of pyridine adsorption IR spectroscopy and ammonia TPD was employed. For both experiments, the samples were pretreated at $300{ }^{\circ} \mathrm{C}$ in an identical fashion to the $\mathrm{CO}_{2}$ TPD experiments. After pretreatment, a background IR spectrum was recorded before saturating the sample with pyridine. Physisorbed pyridine and weakly bound pyridine were removed from the surface of both AlNCs and commercial $\gamma$ $\mathrm{Al}_{2} \mathrm{O}_{3}$ by flushing with helium and heating the surface to 216 ${ }^{\circ} \mathrm{C}$ (Figure 4c). Commercial $\gamma-\mathrm{Al}_{2} \mathrm{O}_{3}$ showed a strong signal for Lewis acid-bound $\left(1445\right.$ and $1610 \mathrm{~cm}^{-1}$ ) and hydrogen-bonded (1440 and $1597 \mathrm{~cm}^{-1}$ ) pyridine species. ${ }^{39}$ No IR signal was observed for AlNCs after the introduction of pyridine, suggesting only few acidic sites on the AlNC surface. Ammonia TPD confirmed the contrasting availability of acid sites on both types of oxide (Figure $4 \mathrm{~d}$ ).

These findings are further confirmed by the selectivity observed in methanol TPD measurements, since the molecular species that desorbs after methanol adsorption can indicate the type of active site on a surface. ${ }^{40}$ Dimethyl ether (DME) was the primary desorption product during methanol TPD measurements of commercial $\gamma-\mathrm{Al}_{2} \mathrm{O}_{3}$ (Figure 4e), confirming the presence of its acidic sites. In contrast, methanol TPD measurements of AlNCs (Figure 4f) found selectivity favoring conversion to $\mathrm{CO}_{2}$, a signature of basic surface sites, in addition to a high quantity of desorbed methanol. ${ }^{40}$

Combined with the observations from rotational spectroscopy, these findings from IR spectroscopy and TPD measurements confirm the proposed OCS catalytic decomposition mechanism. HTC surface intermediates are created by the adsorption of OCS at the many basic sites, likely surface 
hydroxyls, found in the amorphous AlNC oxide. Photothermal heating by resonant absorption of laser illumination at the LSPR of the AlNCs subsequently forms and desorbs $\mathrm{CO}$ or $\mathrm{CO}_{2}+\mathrm{H}_{2} \mathrm{~S}$ depending on the absence or presence of water, respectively. The slow decomposition rate is a consequence of active site poisoning by the remnant sulfur or adsorbed $\mathrm{H}_{2} \mathrm{~S}$.

Isotopic Analysis. With the OCS decomposition mechanisms well understood, we conclude by considering a final attribute of rotational spectroscopy: its ability to discriminate isotopologues and ascertain reaction pathways using labeled reactants or detecting anomalous deviations from natural abundances. Monitoring isotopologues represents a unique strength of $\mathrm{THz}$ rotational spectroscopy since isotopologues of a single molecule are easily distinguishable by their distinct spectral signatures. This can be particularly beneficial for discriminating isotopologues of the same mass that are otherwise challenging to distinguish using techniques such as mass spectrometry or gas chromatography alone. For example, rotational spectroscopy can easily distinguish isotopic isomers, such as the methanol isomers $\mathrm{CH}_{3} \mathrm{OD}$ and $\mathrm{CH}_{2} \mathrm{DOH}$, so that the catalytic pathways may be mapped confidently with isotopic tracers. This absolute recognition specificity and concentration accuracy are not possible with mass spectroscopy or gas chromatography, the widely used competing techniques.

By way of demonstration, the "dry" OCS decomposition reaction was used to probe the formation of three isotopologues of $\mathrm{CO}$ from a nonlabeled OCS precursor whose own isotopologues are present in their natural abundance (Figure 5a). A calculated pressure of 34.0 mTorr of OCS was introduced into the reaction chamber followed by pulsed, $404 \mathrm{~nm}$ wavelength illumination of the AlNC catalyst with $\sim 5 \mathrm{~W} / \mathrm{cm}^{2}$ power density. Over $2 \mathrm{~h}$, the reaction proceeded in a similar manner to the reaction shown in Figure $3 \mathrm{a}$, except that in addition to $\mathrm{CO}$ two additional isotopologues, ${ }^{13} \mathrm{CO}$ and $\mathrm{C}^{18} \mathrm{O}$, were monitored simultaneously. At the end of the reaction, the final calculated pressure of OCS was $<0.01$ mTorr, confirming complete decomposition of OCS. The final calculated pressure of $\mathrm{CO}$ was $35.9 \mathrm{mTorr}$, higher than the pressure of the OCS initially measured by the capacitance manometer of $25.4 \mathrm{mT}$ Torr, because of the fast initial adsorption of OCS on the AlNC surface. The final pressure of ${ }^{13} \mathrm{CO}$ and $\mathrm{C}^{18} \mathrm{O}$ were calculated to be 1.3 and $0.2 \mathrm{mTorr}$, respectively, which correspond to molecular concentrations of 69.9 and 19.4 $\mathrm{pmol} / \mathrm{cm}^{3}$.

Similarly, the four most common isotopologues of OCS $\left({ }^{16} \mathrm{O}^{12} \mathrm{C}^{32} \mathrm{~S},{ }^{16} \mathrm{O}^{12} \mathrm{C}^{34} \mathrm{~S},{ }^{16} \mathrm{O}^{13} \mathrm{C}^{32} \mathrm{~S}\right.$, and $\left.{ }^{18} \mathrm{O}^{12} \mathrm{C}^{32} \mathrm{~S}\right)$ were monitored during the decomposition of a nominal pressure of $30.7 \mathrm{mT}$ Torr of OCS (Figure $5 \mathrm{~b}$ ). The rate of decomposition of each isotope was independent of isotopologue. A subsequent measurement of the OCS isotopologues during decomposition confirmed that isotopic abundances did not change during the reaction; however, the reaction rate had slowed because residual sulfur from the previous measurement had poisoned the active sites. The absence of evidence for a kinetic isotope effect for OCS decomposition reinforces the hypothesis of a thermally driven mechanism on the AlNC surface. ${ }^{13}$ Furthermore, each isotopologue was investigated over nearly a dozen transitions in our experimental apparatus (Figure S7). Even two isotopologues of identical mass, ${ }^{18} \mathrm{OCS}$ and $\mathrm{OC}^{34} \mathrm{~S}$ $(\mathrm{m} / z=62 \mathrm{u})$, were easily differentiated over multiple rotational transitions with frequency-modulated rotational spectroscopy. The ability to monitor low-abundance isotopically labeled products starting with nonlabeled precursors is a unique (a)

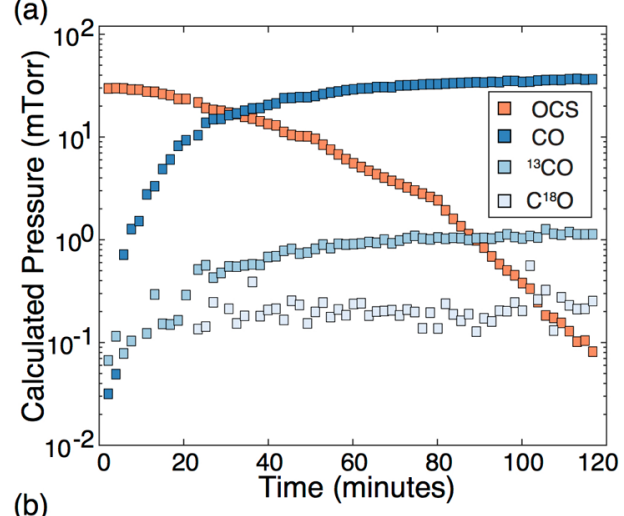

(b)

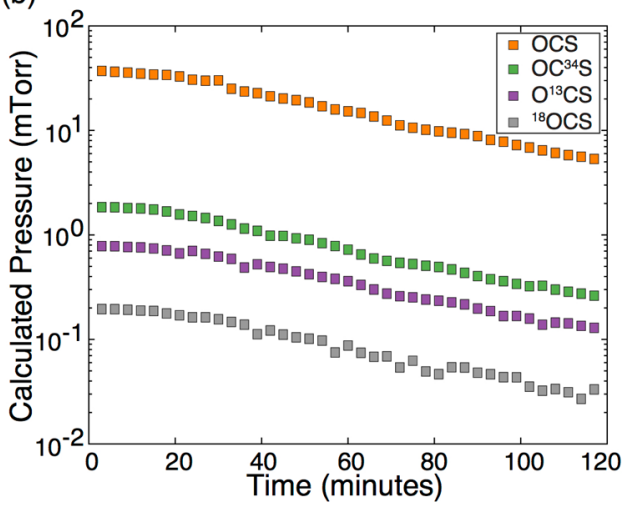

Figure 5. Isotopic analysis of reactant and product gas mixtures. (a) Temporal decomposition of $25.4 \mathrm{mT}$ Torr OCS while monitoring three $\mathrm{CO}$ isotopologues, $\mathrm{CO},{ }^{13} \mathrm{CO}$, and $\mathrm{C}^{18} \mathrm{O}$, which are expected to be $96.5 \%, 1.07 \%$, and $0.198 \%$ abundance, respectively. (b) Rates of reactivity of four OCS isotopes $\left({ }^{16} \mathrm{O}^{12} \mathrm{C}^{32} \mathrm{~S},{ }^{16} \mathrm{O}^{12} \mathrm{C}^{34} \mathrm{~S},{ }^{16} \mathrm{O}^{13} \mathrm{C}^{32} \mathrm{~S}\right.$, and $\left.{ }^{18} \mathrm{O}^{12} \mathrm{C}^{32} \mathrm{~S}\right)$. Throughout each reaction the catalyst was illuminated at $404 \mathrm{~nm}$ with a power density of $\sim 5 \mathrm{~W} / \mathrm{cm}^{2}$. A decrease in OCS decomposition rates from (a) to (b) is due to the formation of surface sulfates and sulphites that occur during the "CO reaction" and poison the active sites.

advantage and confirms the high sensitivity and selectivity achievable with $\mathrm{THz}$ rotational spectroscopy.

\section{CONCLUSIONS}

Terahertz rotational spectroscopy has been introduced as a new tool for identifying and quantifying the composition of gasphase reactants and products during chemical reactions. By studying the decomposition of OCS as a model reaction, we have demonstrated how this technique may be used to monitor plasmon-driven photocatalytic reactions in situ and to measure molecular concentrations quantitatively over the course of the reaction. Reactants and products and their isotopologues were easily distinguished, and time-evolving concentrations were accurately measured to concentrations below 1 nanomolar. The amorphous oxide shell on colloidal AlNCs has been revealed to contain a high number of strongly basic sites compared to commercial $\gamma-\mathrm{Al}_{2} \mathrm{O}_{3}$ under identical pretreatment conditions. These basic sites are the active surface for plasmon-mediated decomposition of OCS over AlNCs; however, the reaction pathway also strongly depends on the $\mathrm{H}_{2} \mathrm{O}$ content of the system. When $\mathrm{H}_{2} \mathrm{O}$ is present, production of $\mathrm{H}_{2} \mathrm{~S}$ is observed and $\mathrm{CO}$ formation is suppressed, supporting an OCS hydrolysis mechanism. When $\mathrm{H}_{2} \mathrm{O}$ is eliminated by high-temperature pretreatment of the plasmonic catalyst, no $\mathrm{H}_{2} \mathrm{~S}$ is evolved and $\mathrm{CO}$ is the sole gas-phase product in stoichiometric yield, 
suggesting a high-temperature OCS decomposition. In both cases, photothermal heating based on the absorption of light by AlNC plasmon-resonant illumination, followed by plasmon decay and photothermal heating, catalyzed OCS decomposition. These results demonstrate that rotational spectroscopy is a powerful approach for monitoring and analyzing in situ gasphase chemical reactions in real time. This experimental system, as described here, is a batch reactor best employed for understanding reaction mechanisms, but this approach could find even more uses as a monitor of flow-reactor systems or through engineering systems coupled to other analytic techniques such as mass spectrometry or gas chromatography.

\section{METHODS}

Rotational Spectrometer. Rotational spectra were obtained using a Virginia Diodes, Inc., amplifier-multiplier chain source spanning the $210-360 \mathrm{GHz}$ region. Only single rotational transitions were probed at a given time, and the transition probed for each isotopologue and molecular species was kept constant throughout the study. Probe radiation from the source horn antenna was collimated by an off-axis parabolic mirror (OAPM) for a beam that filled the $5 \mathrm{~cm}$ diameter, $10 \mathrm{~cm}$ long absorption cell, then concentrated by a second OAPM and received by a horn antenna coupled to a zero-bias Schottky diode detector. Following a matched low-noise transimpedance amplifier and a $30 \mathrm{~dB}$ gain low-noise preamplifier, the signal was band-pass filtered and amplified based on the $f=25 \mathrm{kHz}$ sawtooth modulation that was detected at $2 f$ by a lock-in amplifier with automated phase control, then read out by a computer. Typically, spectral scans spanned $\sim 5 \mathrm{MHz}$ centered on the rotational absorption line, and the modulated line strength was captured every $10 \mathrm{kHz}$. Given the $10 \mathrm{~ms}$ time constant of the lock-in amplifier and the 250 measurement signals averaged for each frequency step, the $\sim 500$ frequency steps required to acquire each spectrum took approximately 1 min. OCS was monitored at $231.061 \mathrm{GHz}(J=18 \rightarrow 19$ rotational transition) with a modulation depth $\omega_{\mathrm{d}}=0.54 \mathrm{MHz}$, while $\mathrm{CO}$ was monitored at $230.538 \mathrm{GHz}(J=1 \rightarrow 2)$ with $\omega_{\mathrm{d}}=$ $0.81 \mathrm{MHz}$ for the decomposition experiment. ${ }^{13} \mathrm{CO}$ was monitored at $330.330 \mathrm{GHz}(J=2 \rightarrow 3)$ with $\omega_{\mathrm{d}}=1.01 \mathrm{MHz}$, and $\mathrm{C}^{18} \mathrm{O}$ was monitored at $339.008 \mathrm{GHz}(J=2 \rightarrow 3)$ with $\omega_{\mathrm{d}}=$ $1.03 \mathrm{MHz}$. All modulation depths were selected to maximize modulated line strength at a given frequency given the Doppler line width of the individual transition. Details about how the modulated spectra were fit to recover the integrated unmodulated Voigt profile and calibrated partial pressure of the gas are provided in the Supporting Information (SI).

Vacuum Chamber and Optical Illumination. The vacuum chamber was composed of KF flange stainless steel vacuum sections except for the CF flange five-way cross reaction and absorption chamber containing the catalyst. A Pfeiffer Hi-Cube compact turbo-molecular pump station achieved base pressures of $<10^{-5}$ Torr and a leak up rate of $3.3 \mathrm{mTorr} / \mathrm{h}$ caused by outgassing from the O-rings in the KF flange connections. A lecture bottle of $>97.5 \%$ purity OCS from Sigma-Aldrich provided the reactant, which was controllably introduced into the reaction chamber as measured by an MKS Baratron capacitance manometer. Details about the AlNC catalysts and the custom stage that held, heated, and measured them are provided in the SI.

The vertical arm of the cross is used for optical illumination by a Coherent Chameleon Ultra II Ti:sapphire tunable laser between 680 and $1080 \mathrm{~nm}$ with a pulse duration of $150 \mathrm{fs}$ and a repetition rate of $80 \mathrm{MHz}$. A second-harmonic generator (Angewandte Physik and Elektronik $\mathrm{GmbH}$, output wavelength $350-530 \mathrm{~nm}$ ) was used to tune the laser to the AlNC plasmon resonance frequency of $\sim 400 \mathrm{~nm}$. The source output of $\sim 100$ $\mathrm{mW}$ was focused to a $1 \mathrm{~mm}$ spot size, yielding a power density of $\sim 5 \mathrm{~W} / \mathrm{cm}^{2}$. Neutral density filters were used to attenuate the output power incident on the catalyst. A camera (Basler Ace) is placed above the vertical chamber arm to monitor the position of the laser spot. A motorized micrometer-controlled mirror mount (T-MM2, Zaber) is used to raster scan the beam over the catalyst surface.

$\mathrm{CO}_{2}$ Pulse Chemisorption Measurements. $\mathrm{CO}_{2}$ pulse chemisorption measurements were performed using a Micromeritics Autochem II 2920 gas analyzer. In a typical experiment, approximately $200 \mathrm{mg}$ of either the $\gamma-\mathrm{Al}_{2} \mathrm{O}_{3}$ (Inframat Materials) or AlNC samples was loaded into a Ushaped sample tube and pretreated at $300-500{ }^{\circ} \mathrm{C}$ in flowing $\mathrm{He}$ (50 sccm, 99.999\%, Airgas) for $30 \mathrm{~min}$, then cooled in flowing $\mathrm{He}$ to $45^{\circ} \mathrm{C}$. Pulse chemisorption measurements were then performed by pulsing calibrated amounts of $10 \% \mathrm{CO}_{2} / \mathrm{He}$ (Airgas) over each material until saturation and measuring the effluent using a thermal conductivity detector. The number of $\mathrm{CO}_{2}$ molecules adsorbed on each material was then normalized by the total BET surface area, measured by $\mathrm{N}_{2}$ physisorption at $77 \mathrm{~K}$ using a Micromeritics ASAP 2020 surface area analyzer to give molecules $/ \mathrm{nm}^{2}$ for each sample.

Temperature-Programmed Desorption Measurements. $\mathrm{CO}_{2}$ TPD experiments were performed immediately after $\mathrm{CO}_{2}$ pulse chemisorption measurements by ramping to $500{ }^{\circ} \mathrm{C}$ at a rate of $30{ }^{\circ} \mathrm{C} / \mathrm{min}$ and holding for $30 \mathrm{~min}$ under flowing $\mathrm{He}$. $\mathrm{NH}_{3}$ TPD measurements were performed by pretreating each sample at $300{ }^{\circ} \mathrm{C}$ in flowing $\mathrm{He}$, cooling to 120 ${ }^{\circ} \mathrm{C}$, and saturating the sample with $15 \% \mathrm{NH}_{3} / \mathrm{He}$ (Airgas) for $30 \mathrm{~min}$. Following a $60 \mathrm{~min}$ flush with helium at $120^{\circ} \mathrm{C}$, the TPD was then performed at $10{ }^{\circ} \mathrm{C} / \mathrm{min}$ up to a temperature of $500{ }^{\circ} \mathrm{C}$ and holding for $60 \mathrm{~min}$. Methanol (MeOH) TPD experiments followed the same pretreatment procedure as $\mathrm{NH}_{3}$ TPD measurements, followed by cooling to $100{ }^{\circ} \mathrm{C}$ in flowing He. Helium was then flowed through the vapor generator (held at $35{ }^{\circ} \mathrm{C}$ ) containing anhydrous methanol (99.8\%, SigmaAldrich) and over the samples at $100{ }^{\circ} \mathrm{C}$ for $30 \mathrm{~min}$. Following $\mathrm{MeOH}$ adsorption, each sample was flushed with $\mathrm{He}$ for 60 $\min$ at $100{ }^{\circ} \mathrm{C}$. The temperature of $100{ }^{\circ} \mathrm{C}$ ensured a saturation coverage of $\mathrm{MeOH}$ adsorption, while minimizing physically adsorbed $\mathrm{MeOH}^{40} \mathrm{TPD}$ measurements were then performed by ramping to $500{ }^{\circ} \mathrm{C}$ at a rate of $10{ }^{\circ} \mathrm{C} / \mathrm{min}$ while monitoring the effluent stream with online mass spectrometry (HALO 201, Hiden Analytical Inc.). The following $m / z$ values were used to detect each product: $m / z=28$ for CO, $m / z=30$ for $\mathrm{H}_{2} \mathrm{CO}, m /$ $z=31$ for $\mathrm{MeOH}, m / z=44$ for $\mathrm{CO}_{2}, m / z=45$ for DME, and $m / z=76$ for dimethoxymethane (DMM). No CO, $\mathrm{H}_{2} \mathrm{CO}$, or DMM formation was observed during $\mathrm{MeOH}$ TPD experiments. The time delay between the reactor and mass spectrometer was corrected, and each $\mathrm{m} / z$ signal was quantified using calibrations and normalized to the surface area of each sample to give molecules $/ \mathrm{s} \cdot \mathrm{nm}^{2}$.

Infrared Spectroscopy Measurements. Pyridine IR experiments were performed in a high-temperature reaction chamber (Harrick Scientific) equipped with $\mathrm{ZnSe}$ windows and mounted inside a diffuse reflectance adapter (Harrick Scientific) and coupled to a Thermo Scientific Nicolet iS10 FTIR spectrometer with a liquid-nitrogen-cooled $\mathrm{HgCdTe}$ (MCT) detector. All measurements were made while purging 
the FTIR and diffuse reflection accessory with dry $\mathrm{N}_{2}$. Each sample was loaded into the reaction chamber, followed by pretreatment in flowing $\mathrm{Ar}$ (50 sccm, 99.999\%, Airgas) at 300 ${ }^{\circ} \mathrm{C}$ for $30 \mathrm{~min}$ (note: $300{ }^{\circ} \mathrm{C}$ represents the sample surface temperature, which was calibrated using an optical pyrometer). Following pretreatment, the samples were cooled to $216^{\circ} \mathrm{C}$, where a background IR spectrum was measured by averaging 128 scans at a resolution of $4 \mathrm{~cm}^{-1}$. Pyridine adsorption was accomplished by cooling the sample to ambient conditions, flowing Ar through a pyridine bubbler/vapor generator at room temperature until the sample was saturated $(\sim 5-10 \mathrm{~min})$. Physically adsorbed pyridine was then removed by flushing with pure $\mathrm{Ar}$ and slowly ramping the temperature to $216{ }^{\circ} \mathrm{C}(\sim 10$ ${ }^{\circ} \mathrm{C} / \mathrm{min}$ ), giving the spectra observed in Figure $4 \mathrm{c}$.

\section{ASSOCIATED CONTENT}

\section{S Supporting Information}

The Supporting Information is available free of charge on the ACS Publications website at DOI: 10.1021/acsphotonics.8b00342.

Additional details regarding materials and experimental methods; description of the quantification procedure and experimental calibration curves, description of the limits of detection, and supplementary figures (PDF)

\section{AUTHOR INFORMATION}

\section{Corresponding Authors}

*E-mail (N. J. Halas): halas@rice.edu.

*E-mail (H. O. Everitt): he5@rice.edu.

ORCID ${ }^{-0}$

Dayne F. Swearer: 0000-0003-0274-4815

Phillip Christopher: 0000-0002-4898-5510

Naomi J. Halas: 0000-0002-8461-8494

Henry O. Everitt: 0000-0002-8141-3768

\section{Present Address}

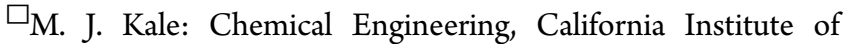
Technology, Pasadena, California 91125, United States.

\section{Author Contributions}

The manuscript was written through contributions of all authors. All authors have given approval to the final version of the manuscript.

\section{Author Contributions}

${ }^{\mathbb{I}}$ D. F. Swearer and S. Gottheim contributed equally.

\section{Notes}

The authors declare no competing financial interest.

\section{ACKNOWLEDGMENTS}

The authors thank C. Neese and M. Reish for discussions regarding rotational spectroscopy, J. Yang, A. Alabastri, and P. Nordlander for discussions regarding photothermal heating of the $\mathrm{Al} \mathrm{NCs} \mathrm{in} \mathrm{vacuo,} \mathrm{and} \mathrm{Hossein} \mathrm{Robatjazi} \mathrm{for} \mathrm{the} \mathrm{instrument}$ schematic in Figure 1a. This work was funded by the Air Force Office of Scientific Research Multidisciplinary Research Program of the University Research Initiative (AFOSR MURI FA9550-15-1-0022), the Army Research Office (MURI W911NF-12-1-0407), Defense Threat Reduction Agency (HDTRA 1-16-1-0042), the Army Aviation and Missile RD\&E Center In-house Laboratory Innovative Research program, and the Welch Foundation under grant C-1220 (N.J.H.). D.F.S. acknowledges the National Science Foundation for a Graduate Research Fellowship under grant no. 1450681.

\section{REFERENCES}

(1) Townes, C. W.; Schlawlow, A. L. Microwave Spectroscopy; McGraw Hill, 1955.

(2) Gordy, W.; Cook, R. L. Microwave Molecular Spectroscopy; WileyInterscience: New York, 1984.

(3) Zaleski, D. P.; Harding, L. B.; Klippenstein, S. J.; Ruscic, B.; Prozument, K. Time-Resolved Kinetic Chirped-Pulse Rotational Spectroscopy in a Room-Temperature Flow Reactor. J. Phys. Chem. Lett. 2017, 8 (24), 6180-6188.

(4) Jet Propolsion Laboratory Molecular Spectroscopy Database https://spec.jpl.nasa.gov/ (accessed Oct 1, 2017).

(5) Splatalogue Database for Astronomical Spectroscopy https:// www.cv.nrao.edu/php/splat/ (accessed Oct 15, 2017).

(6) Song, J.; Zhou, J.; Duan, H. Self-Assembled Plasmonic Vesicles of SERS-Encoded Amphiphilic Gold Nanoparticles for Cancer Cell Targeting and Traceable Intracellular Drug Delivery. J. Am. Chem. Soc. 2012, 134, 13458-13469.

(7) Liu, N.; Tang, M. L.; Hentschel, M.; Giessen, H.; Alivisatos, A. P. Nanoantenna-enhanced Gas Sensing in a Single Tailored Nanofocus. Nat. Mater. 2011, 10 (8), 631-636.

(8) Haes, A.; Haynes, C.; Mcfarland, A. D.; Schatz, G. C.; Van Duyne, R. P.; Zou, S. Plasmonic Materials for Surface-Enhanced Sensing and Spectroscopy. MRS Bull. 2005, 30, 368.

(9) Boltasseva, A.; Atwater, H. A. Low-Loss Plasmonic Metamaterials. Science (Washington, DC, U. S.) 2011, 331, 290-292.

(10) Linic, S.; Aslam, U.; Boerigter, C.; Morabito, M. Photochemical Transformations on Plasmonic Metal Nanoparticles. Nat. Mater. 2015, 14 (6), 567-576.

(11) Mubeen, S.; Lee, J.; Singh, N.; Krämer, S.; Stucky, G. D.; Moskovits, M. An Autonomous Photosynthetic Device in which all Charge Carriers Derive from Surface Plasmons. Nat. Nanotechnol. 2013, 8, 247-251.

(12) Seh, Z. W.; Liu, S.; Low, M.; Zhang, S.; Liu, Z. Janus Au-TiO Photocatalysts with Strong Localization of Plasmonic Near-Fields for Efficient Visible-Light Hydrogen Generation. Adv. Mater. 2012, 24, 2310-2314.

(13) Christopher, P.; Xin, H.; Linic, S. Visible-Light-Enhanced Catalytic Oxidation Reactions on Plasmonic Silver Nanostructures. Nat. Chem. 2011, 3 (6), 467-472.

(14) Li, K.; Hogan, N. J.; Kale, M. J.; Halas, N. J.; Nordlander, P.; Christopher, P. Balancing Near-Field Enhancement, Absorption, and Scattering for Effective Antenna - Reactor Plasmonic Photocatalysis. Nano Lett. 2017, 17, 3710-3717.

(15) Swearer, D. F.; Zhao, H.; Zhou, L.; Zhang, C.; Robatjazi, H.; Martirez, J. M. P.; Krauter, C. M.; Yazdi, S.; McClain, M. J.; Ringe, E.; Carter, E. A.; Nordlander, P.; Halas, N. J. Heterometallic AntennaReactor Complexes for Photocatalysis. Proc. Natl. Acad. Sci. U. S. A. 2016, 113 (32), 8916-8920.

(16) Robatjazi, H.; Zhao, H.; Swearer, D. F.; Hogan, N. J.; Zhou, L.; Alabastri, A.; McClain, M. J.; Nordlander, P.; Halas, N. J. PlasmonInduced Selective Carbon Dioxide Conversion on Earth-Abundant Aluminum-Cuprous Oxide Antenna-Reactor Nanoparticles. Nat. Commun. 2017, 8 (1), 27.

(17) Zhang, X.; Li, X.; Zhang, D.; Su, N. Q.; Yang, W.; Everitt, H. O.; Liu, J. Product Selectivity in Plasmonic Photocatalysis for Carbon Dioxide Hydrogenation. Nat. Commun. 2017, 8, 14542.

(18) McClain, M. J.; Schlather, A.; Ringe, E.; King, N. S.; Liu, L.; Manjavacas, A.; Knight, M.; Kumar, I.; Whitmire, K. H.; Everitt, H. O.; Nordlander, P.; Halas, N. J. Aluminum Nanocrystals. Nano Lett. 2015, 15 (4), 2751-2755.

(19) Pickett, H. M.; Cohen, E. A.; Delitsky, M. L.; Pearson, J. C.; Muller, H. S. P. Submillimeter, Millimeter, and Microwave Spectral Line Catalog. J. Quant. Spectrosc. Radiat. Transfer 1998, 60 (5), 883890.

(20) Kisiel, Z.; Millen, D. J. Peak Absorption Coefficients of Microwave Absorption Lines of Carbonyl Sulphide. J. Phys. Chem. Ref. Data 1982, 101 (1), 101-117. 
(21) Silver, J. A. Frequency-Modulation Spectroscopy for Trace Species Detection: Theory and Comparison Among Experimental Methods. Appl. Opt. 1992, 31 (6), 707-717.

(22) Abrarov, S. M.; Quine, B. M. A Rational Approximation for Efficient Computation of the Voigt Function in Quantitative Spectroscopy. J. Math. Res. 2015, 7 (2), 163-174.

(23) Svoronos, P. D. N.; Bruno, T. J. Carbonyl Sulfide : A Review of Its Chemistry and Properties Pertaining to Carbonyl Sulfide COS in Plants. Ind. Eng. Chem. Res. 2002, 41 (22), 5321-5336.

(24) Ferm, R. J. The Chemistry of Carbonyl Sulfide. Chem. Rev. 1957, 57, 621-640.

(25) Wakker, J. P.; Gerritsen, A. W.; Moulijn, J. A. High Temperature $\mathrm{H} 2 \mathrm{~S}$ and $\mathrm{COS}$ Removal with $\mathrm{MnO}$ and $\mathrm{FeO}$ on $\gamma$ - $\mathrm{Al}_{2} \mathrm{O}_{3}$ Acceptors. Ind. Eng. Chem. Res. 1993, 31, 139-149.

(26) Williams, B. P.; Young, N. C.; West, J.; Rhodes, C.; Hutchings, G. J. Carbonyl sulphide hydrolysis using alumina catalysts. Catal. Today 1999, 49, 99-104.

(27) Zhao, Z.; Stickel, R. E.; Wine, P. H. Quantum Yield for Carbon Monoxide Production in the $248 \mathrm{~nm}$ Photodissociation of Carbonyl Sulfide (OCS). Geophys. Res. Lett. 1995, 22 (5), 615-618.

(28) Liu, J.; Yu, Y.; Mu, Y.; He, H. Mechanism of Heterogeneous Oxidation of Carbonyl Sulfide on $\mathrm{Al}_{2} \mathrm{O}_{3}:$ An in Situ Diffuse Reflectance Infrared Fourier Transform Spectroscopy Investigation. J. Phys. Chem. B 2006, 670, 3225-3230.

(29) He, H.; Liu, J.; Mu, Y. Heterogeneous Oxidation of Carbonyl Sulfide on Atmospheric Particles and Alumina. Environ. Sci. Technol. 2005, 39, 9637-9642.

(30) West, J.; Williams, B. P.; Young, N. C.; Rhodes, C.; Hutchings, G. J. New Directions for COS Hydrolysis: Low Temperature Alumina Catalysts. In Studies in Surface Science Catalysis; Elsevier Masson SAS, 1998; Vol. 119, pp 373-378.

(31) Hoggan, P. E.; Aboulayt, A.; Pieplu, A.; Nortier, P.; Lavalley, J. C. Mechanism of COS Hydrolysis on Alumina. J. Catal. 1994, 149, 300-306.

(32) Tan, S.; Li, C.; Liang, S.; Guo, H. Compensation Effect in Catalytic Hydrolysis of Carbonyl Sulfide at Lower Temperatures. Catal. Lett. 1991, 8, 155-168.

(33) Knight, M. W.; King, N. S.; Liu, L.; Everitt, H. O.; Nordlander, P.; Halas, N. J. Aluminum for Plasmonics. ACS Nano 2014, 8 (1), 834-840.

(34) Liu, Y.; He, H.; Mu, Y. Heterogeneous reactivity of carbonyl sulfide on $\alpha-\mathrm{Al}_{2} \mathrm{O}_{3}$ and $\gamma-\mathrm{Al}_{2} \mathrm{O}_{3}$. Atmos. Environ. 2008, 42, 960-969.

(35) Partington, J. R.; Neville, H. H. The Thermal Decomposition of Carbonyl Sulphide. J. Chem. Soc. 1951, 0, 1230-1237.

(36) Liu, Y.; Ma, Q.; He, H. Comparative Study of the Effect of Water on the Heterogeneous Reactions of Carbonyl Sulfide on the surface of $\alpha-\mathrm{Al}_{2} \mathrm{O}_{3}$ and $\mathrm{MgO}$. Atmos. Chem. Phys. 2009, 9, 6273-6286. (37) Hay, A. J.; Belford, R. L. High-Temperature Gas-Kinetic Study of Carbonyl Sulfide Pyrolysis Performed with a Shock Tube and Quadrupole Mass Filter. J. Chem. Phys. 1967, 47 (10), 3944-2960.

(38) Bachelier, J.; Aboulayt, A.; Lavalley, J. C.; Legendre, O.; Luck, F. Activity of Different Metal Oxides Towards COS Hydrolysis: Effect of $\mathrm{SO}_{2}$ and Sulfation. Catal. Today 1993, 17, 55-62.

(39) Tamura, M.; Shimizu, K.; Satsuma, A. Comprehensive IR Study on Acid/Base Properties of Metal Oxides. Appl. Catal., A 2012, 433434, 135-145.

(40) Badlani, M.; Wachs, I. E. Methanol: A "Smart" Chemical Probe Molecule. Catal. Lett. 2001, 75 (3-4), 137-149. 